\title{
Responses to Reviewer
}

Manuscript Number: APP-2016-03-0869

Title: Development of bio-based electromagnetic wave-absorbing composites using various magnetic metal and carbon materials

Authors: Shinji Kanehashi, Hiroki Oyagi, Toraki Iwamaru, Shota Ando, Kazukiyo Nagai, Shinichiro Uekusa, and Tetsuo Miyakoshi

Thank you very much for your useful comments. We considered your comments and revised the manuscript. We have a good opportunity to improve our paper. The responses to your comments are summarized below.

\section{Q. 1. Authors can explain the benefits of the material widely.}

A.1. Thank you very much for your comment. This is an important point of this work. Traditionally, natural lacquer is known to as a durable beautiful coating materials and therefore, they have been used in decoration for various articles, indicating it can be available only for coating materials, but are limited in other applications. To solve this limitation, we have been focusing on the property of natural phenolic compounds and bio-based materials derived from them. This paper is first report for natural lacquer-based composites containing highly content of fillers. And this paper would provide novel possibility of use of natural lacquer. According to your comment, we revised and added benefits of natural lacquer in introduction.

Q. 2. Figure 6 and Figure 7 can be combined.

A.2. According to your comment, we revised it.

This is the author manuscript accepted for publication and has undergone full peer review but has not been through the copyediting, typesetting, pagination and proofreading process, which may lead to differences between this version and the Version record. Please cite this article as doi:10.1002/ app.44131. 


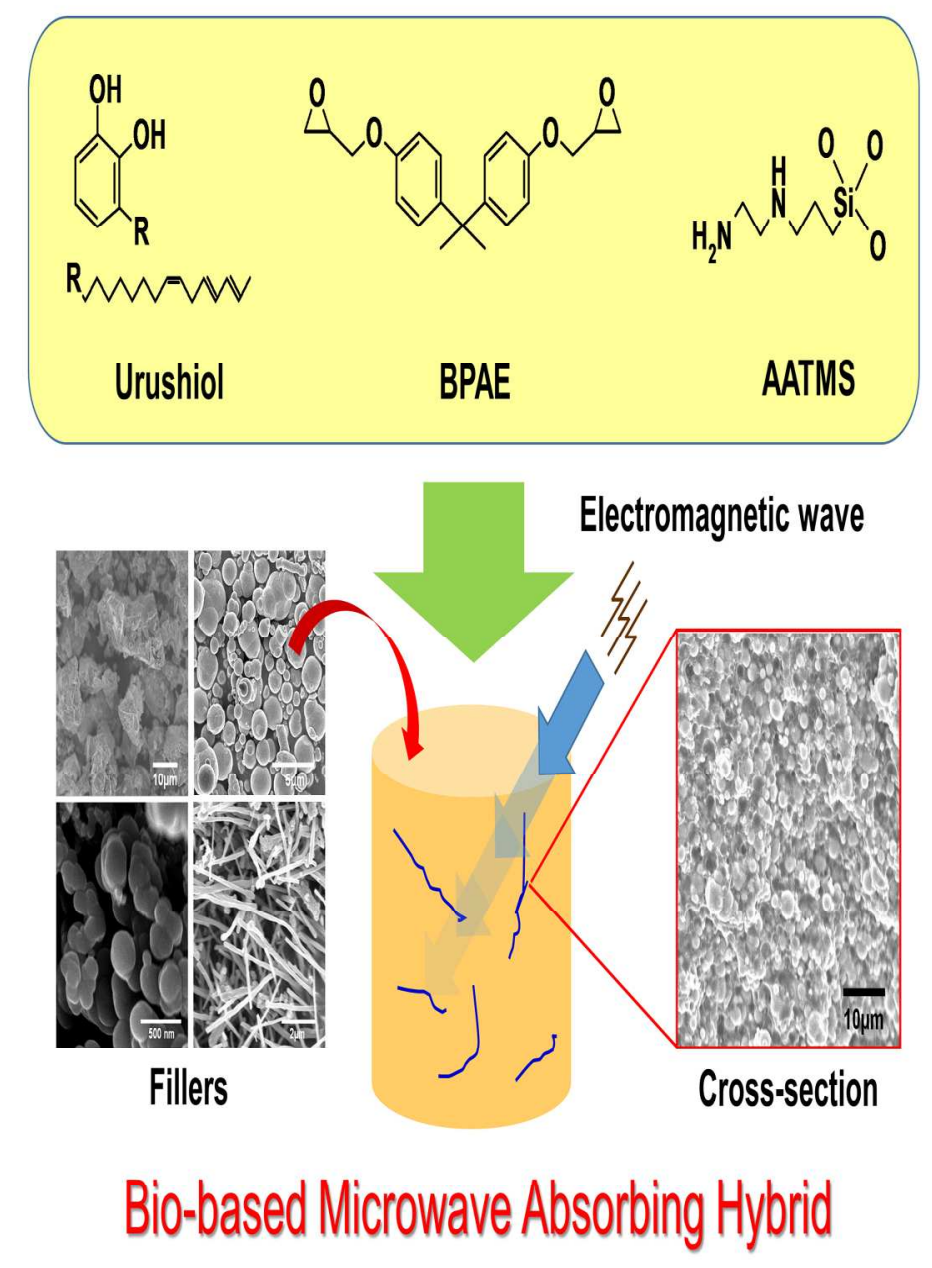

$181 \times 190 \mathrm{~mm}(300 \times 300 \mathrm{DPI})$

John Wiley \& Sons, Inc.

This article is protected by copyright. All rights reserved. 


\section{Revised manuscript}

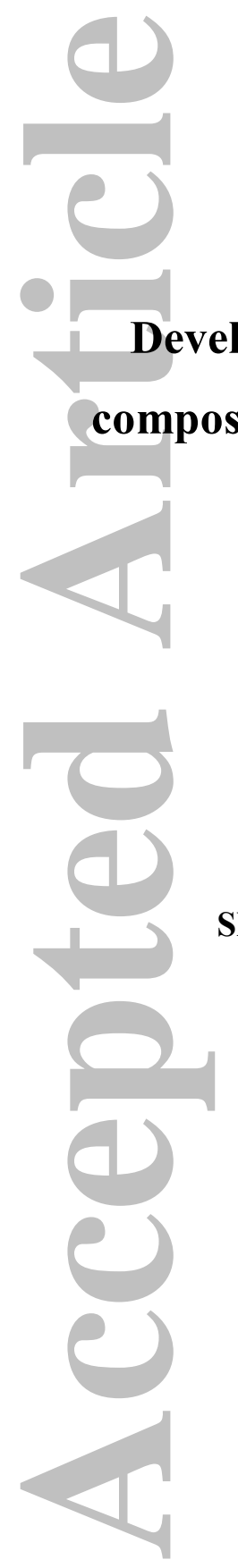

Shinji Kanehashi, ${ }^{1,2}$ Hiroki Oyagi, ${ }^{2}$ Toraki Iwamaru, ${ }^{2}$ Shota Ando, ${ }^{2}$ Kazukiyo Nagai, ${ }^{2}$ Shinichiro Uekusa, ${ }^{2}$ and Tetsuo Miyakoshi ${ }^{* 2}$

${ }^{1}$ Department of Organic and Polymer Materials Chemistry, Tokyo University of Agriculture and Technology, 2-24-16 Nakacho, Koganei-shi, Tokyo 184-8588 Japan

${ }^{2}$ School of Science and Technology, Meiji University, 1-1-1 Higashi-mita, Tama-ku, Kawasaki 214-8571 Japan

* Correspondence to Tetsuo Miyakoshi

Tel : +81-44-934-7203, Fax : +81-44-934-7906

E-mail : miya@meiji.ac.jp

John Wiley \& Sons, Inc.

This article is protected by copyright. All rights reserved. 


\section{ABSTRACT}

Preparation and characterization of bio-based electromagnetic wave-absorbing composite material derived from natural lacquer as a renewable resource using microwave absorption fillers including Ni-Zn ferrite and carbonyl iron (CI) as magnetic metals and soot and carbon nanotubes (CNT) as carbon materials were investigated in terms of the gel content, hardness, drying properties, and electromagnetic wave absorption property. Interestingly, composites using ferrite and CI can contain up to $320 \mathrm{wt} \%$ and $550 \mathrm{wt} \%$, respectively. This quite high loading capacity of metal fillers into a natural lacquer-based could be based on the high compatibility between a filler and natural lacquer, indicating that the natural lacquer works as

a binder for these metals. The morphology of the bio-based composite was characterized by scanning electron microscopy. The electromagnetic wave absorption properties of composites were characterized in a frequency range of 0.05 and $20 \mathrm{GHz}$ by the reflection loss measurement method in terms of kind of fillers and filler loading. The natural lacquer did not affect the absorption properties of fillers. Bio-based composites showed over $99 \%$ electromagnetic absorption in the frequency range of $3.0-4.0 \mathrm{GHz}$ for $280 \mathrm{wt} \%$ ferrite and of 8.9-9.7 GHz for $200 \mathrm{wt} \%$ carbonyl iron. Conversely, 10 and $20 \mathrm{wt} \%$ soot exhibited good performance $(\mathrm{RL}<-20 \mathrm{~dB}$ ) between 16.5 and 17.3 and between 8.8 and $9.2 \mathrm{GHz}$, respectively. $\mathrm{RL}<-20 \mathrm{~dB}$ areas of CNT composites were $10.4-11.0 \mathrm{GHz}$ for $5 \mathrm{wt} \%$ and 14.6-15.2 GHz for $10 \mathrm{wt} \%$. Hence, natural lacquer can be used as a binder material for not only electromagnetic absorption materials, but also the other composites.

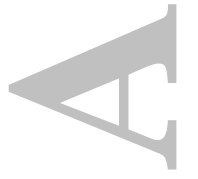




\section{INTRODUCTION}

Recently, electromagnetic wave applications such as electrical and electronic devices used in daily life, industry, hospitals, and the military have earned much attention. In these fields, electromagnetic wave absorption materials play an important role in realizing a comfortable environment. Electromagnetic wave absorption materials normally have been used as composite materials prepared from dielectric or magnetic fillers and polymers. As fillers in this application, carbonyl iron $(\mathrm{CI}),{ }^{1-4}$ carbon, ${ }^{5-7}$ carbon nanotube $(\mathrm{CNT}),{ }^{2,8}$ and magnetic compounds containing $\mathrm{Fe}, \mathrm{Co}$, and $\mathrm{Ni}{ }^{5-10}$ improve the electromagnetic wave absorption properties. Epoxy, ${ }^{1,4,5,8,9}$ resins and rubbery polymers ${ }^{11-13}$ as base polymer/binder

materials have been employed as the wave absorption materials with these fillers. Conversely, researchers normally focus on their investigations on development and improvement of novel absorption filler particles rather than base polymer materials. Most of these materials are used with oil-based compounds. To date, there has been no report on the use of bio-based electromagnetic wave absorption materials.

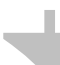

Developments of functional bio-based polymer materials have been received much attention from the environmental concerns in recent years. ${ }^{14-17}$ Natural lacquer is one of the natural polyphenolic compounds which is well known as a traditional natural cross-linked polymer. This natural lacquer sap consists of urushiol, which contains C15 catechols with unsaturated hydrocarbons at positions 3 or 4, water, a gummy substance, a nitrogenous material, and laccase. ${ }^{18,19}$ Natural lacquers have durable beautiful surface and therefore, have been used in the various articles and objects for the protection and decoration. Natural lacquer can be cured by enzymatic and oxidative polymerization in the presence of moisture and laccase without any organic solvent. ${ }^{20}$ Therefore, this natural lacquer has great potential in terms of environmentally friendly materials. In addition, natural lacquer can contain various metal compound additives such as iron oxides to stabilize the color. ${ }^{21}$ Traditionally, 
it is known that this iron oxide disperses well in natural lacquer because lacquer and iron oxide are compatible. Therefore, natural lacquer would be expected as a good compatible property with metals and worked as base polymer/binder for composites. Therefore, natural lacquer-based polymer materials have been investigated according to their unique property. $^{19,22-25}$

(1) However, crosslinking reactions (i.e., drying process) progress slowly compared with other conventional organic coatings because the drying process proceeds based on enzymatic and oxidative polymerization. ${ }^{24,26}$ This means that the drying process of natural lacquer is relatively sensitive and strongly affected by environmental conditions such as moisture and

temperature. Furthermore, it is difficult to fabricate thick resin products from natural lacquer alone due to the nature of natural lacquer. Therefore, natural lacquers can be available only for coating materials, but they are very limited in further novel applications by these issues. We have been focusing on development of bio-based functional materials derived from natural phenolic compounds (e.g., natural lacquer and cashew nut shell liquid) to find further possible effective utilization of natural phenols. For example, we previously developed a thick bio-based composites fabricated by chemical reactions of urushiol, epoxy, and organic silane compounds at room temperature. ${ }^{23}$ In addition, we reported the electromagnetic wave absorption materials using natural lacquer in recent years. ${ }^{27}$

In the present work, we developed the natural lacquer-based novel materials to provide novel possibility of the effective utilization. Herein, we have investigated the preparation of bio-based electromagnetic wave absorption materials derived from natural lacquer and various dielectric or magnetic fillers in terms of their kinds of fillers and loading on the performance.

\section{EXPERIMENTAL}




\section{Chemicals}

The natural lacquer used as a renewable resource was purchased from Doityu Shoten Co., Ltd., Osaka, Japan. Urushiol and lipid components of the lacquer were extracted from raw lacquer sap as reported previously. ${ }^{26}$ Bisphenol A-type epoxy resin (BPAE, Epoxyclear 305114) was purchased from I-Resin Co., Ltd., Japan, and used without further purification. An organic silane compound, $N$-(2-aminomethyl)-3-aminopropyl trimethoxysilane (AATMS) was purchased from Tokyo Chemical Industry Co., Ltd., Japan. Ni/Zn-type ferrite and carbonyl iron (CI) as magnetic metal fillers were purchased from Toda Kogyou Corp., Japan, and BASF Japan, Ltd., Japan, respectively. Amorphous soot and single-wall carbon

nanotube (CNT) as carbon materials were purchased from Minowa Shikkou, Japan, and Showa Denko K.K., Japan, respectively. All materials were used without further purification.

\section{Film and Composite Preparation}

Composite film was prepared using a $76 \mu \mathrm{m}$ applicator (Yoshimitsu Seiki, Tokyo, Japan) at $23^{\circ} \mathrm{C} \pm 1{ }^{\circ} \mathrm{C}$ to investigate the optimum proportions of natural lacquer, BPAE, and AATMS. The film was stored in the dark at $25^{\circ} \mathrm{C}$ and $50 \% \mathrm{RH}$ to evaluate the drying and hardness properties. For thick composite preparations, mixtures of natural lacquer, BPAE, organosilicon compounds, and microwave absorption fillers were poured into a fluororesin tube (outside diameter: $16 \mathrm{~mm}$, inside: $14 \mathrm{~mm}$ ) at $23^{\circ} \mathrm{C} \pm 1^{\circ} \mathrm{C}$. The filler loading of composites were up to $320 \mathrm{wt} \%$ for ferrite, from $550 \mathrm{wt} \%$ for carbonyl iron, $20 \mathrm{wt} \%$ for soot, and $10 \mathrm{wt} \%$ for CNT. After three days, the formed thick composite was removed from the tube.

\section{Characterization}


The molecular weight of the composite was determined at $40^{\circ} \mathrm{C}$ by aqueous phase gel permeation chromatography (GPC; TSK-gel column $\alpha-3000, \alpha-4000$ and $\alpha-\mathrm{M}, \phi 7.8 \mathrm{~mm} \times 300$ $\mathrm{mm} \times 3$, Tosoh Co. Ltd., Tokyo, Japan) using dimethylformamide (DMF) as an eluent with 0.01 mol $\mathrm{LiBr}$ on a high-performance liquid chromatography system using an RI-8012 refractive-index detector with polystyrene standards. The drying of the epoxy coatings at $23^{\circ} \mathrm{C} \pm 1{ }^{\circ} \mathrm{C}$ can be divided into three stages: dust-free dry, touch-free dry, and hardened dry (HD). Each stage was measured using an automatic drying time recorder (RC auto-recorder of paint drying time, TaiYu Co. Ltd., Osaka, Japan) at $23^{\circ} \mathrm{C} \pm 1{ }^{\circ} \mathrm{C}$ and $50 \%$ relative humidity. The pencil hardness is based on the current national standard of GB/T6739-1996. H and B indicate the hardness and softness, respectively, of tested coatings, and higher numbers express the relative hardness or softness of the tested coatings. F and HB indicate medium hardness. However, $\mathrm{F}$ is a slightly harder coating than HB. In the present study, pencil lead hardness was determined using a C-221 pencil hardness tester (Yoshimitsu Seiki, Tokyo, Japan) at $23^{\circ} \mathrm{C} \pm 1{ }^{\circ} \mathrm{C}$. The gel contents of the natural lacquer and bio-based composites were determined by immersion in acetone at $23^{\circ} \mathrm{C} \pm 1^{\circ} \mathrm{C}$ for $24 \mathrm{~h}$. After immersion, the non-soluble parts were dried well and weighed. The gel content was calculated by the following equation:

$$
\text { Gel content }(\%)=\frac{w_{1}}{w_{0}} \times 100
$$

where $w_{1}$ and $w_{0}$ are the weight of the insoluble fraction and the original weight of the completely dried samples, respectively. Scanning electron microscopy (SEM) of cross-sections of bio-based composites was performed using a high-resolution field emission scanning electron microscope (S5200, JEOL Ltd., Tokyo, Japan). The microwave absorption properties of samples were measured by the reflection loss (RL) measurement method and a vector network analyzer (Agilent 8722ES) with a short-backed cylindrical 
waveguide sample holder whose dimensions were $3.0 \mathrm{~mm}$ in inner diameter, $7.0 \mathrm{~mm}$ in outer diameter, and $5.0 \mathrm{~mm}$ in thickness. Complex permeability and complex permittivity were extracted in the frequency range of 0.05 to $20 \mathrm{GHz}$ from S-parameter transmission data using the Nicolson-Ross method as electromagnetic wave absorption parameters. ${ }^{27}$ The RL curves were calculated following equations: ${ }^{9}$

$$
\begin{gathered}
Z_{\text {in }}=Z_{0}\left(\frac{\mu_{r}}{\varepsilon_{r}}\right)^{0.5} \tanh \left\{\left(j \frac{2 \pi f d}{c}\right)\left(\mu_{r} \varepsilon_{r}\right)^{0.5}\right\} \\
\mathrm{RL}=20 \log \left|\frac{Z_{\text {in }}-Z_{0}}{Z_{\text {in }}+Z_{0}}\right|
\end{gathered}
$$

where $\mu_{r}$ and $\varepsilon_{r}$ are relative permeability and permittivity, $f$ is the frequency of the electromagnetic wave, $d$ the thickness of sample, $c$ the velocity of light, $Z_{0}$ the impedance of air, and $Z_{\text {in }}$ the input impedance of sample.

\section{RESULTS AND DISCUSSION}

The molecular weight properties of bio-based composites prepared with various proportions of BPAE and AATMS are summarized in Table 1. The base natural lacquer showed the lowest polymer concentration and molecular weight. As the AATMS organic silane concentration increased, the polymer concentration and molecular weight tended to increase, indicating that an effective sol-gel reaction between organic silane and urushiol had occurred. On the other hand, a high BPAE concentration decreased the polymer concentration, indicating that excess BPAE inhibits the sol-gel reaction. Based on these results, the polymer concentration and molecular weight are more strongly affected by the organic silane concentration than that of BPAE. The drying and hardness properties of bio-based composites are summarized in Table 2. The base natural lacquer required longer to dry than other composites. The addition of BPAE and silane compound to the natural lacquer significantly improved the drying property due to the sol-gel and crosslink reaction among 
these compounds. Based on the drying time, composites with $5 \mathrm{wt} \%$ AATMS dried more rapidly than the other composites. As expected from the molecular weight properties of composites, a high concentration of BPAE seems to improve the drying rate, but there is no obvious trend in the hardness.

Figure 2 presents the gel contents of the natural lacquer and bio-based composites. As expected from the drying and hardness properties of composites, the gel contents of all composites were higher than that of the natural lacquer, indicating that the composites prepared from AATMS and BPAE had a higher cross-link density than the natural lacquer. In addition, the BPAE concentration with the same amount of $5 \mathrm{wt} \%$ AATMS increased (e.g., Nos. 2-5) with decreasing gel content. Based on these results, the best condition for preparation of composites using AATMS organic silane compound and BPAE using natural lacquer was estimated to be $5 \mathrm{wt} \%$ of AATMS and $5 \mathrm{wt} \%$ of BPAE (Entry 2), which is also smallest amount of additives tested. Therefore, preparation of the electromagnetic wave absorption composite was based on the addition of $5 \mathrm{wt} \%$ AATMS and $5 \mathrm{wt} \%$ BPAE.

Generally, the moldability of a composite material is liable to be reduced with increasing filler concentration because the excess filler could become aggregated and increase the rigidity of the composite. However, we have successfully prepared bio-based composites containing up to $320 \mathrm{wt} \%$ ferrite and $550 \mathrm{wt} \% \mathrm{CI}$ in magnetic metal systems, respectively. In addition, these magnetic metal particles were dispersed uniformly in a natural lacquer-based composite due to their smooth surfaces and sphericity. This result indicates that the natural lacquer has great compatibility with metal fillers and works as a binder of the fillers. Traditionally, natural lacquer was used with pigments such as Bengal red (iron oxide), iron powder, and coal to change the color. ${ }^{21}$ This compatibility with metal fillers is known as one of the properties of natural lacquer. Therefore, we hypothesized that natural lacquer-based composite could contain high concentrations of metal fillers. 
Figure 3 presents the SEM images of fillers used as electromagnetic wave absorption particles. The sizes of ferrite crystals and CI particles were estimated to be $10-30 \mu \mathrm{m}$ and $1-3 \mu \mathrm{m}$ spheres, respectively. Soot particles were spherical with a size around $0.5-1.0 \mu \mathrm{m}$, while single wall CNTs were $0.5 \mu \mathrm{m}$ in diameter. Figure 4 presents the cross-sectional SEM images of natural lacquer and bio-based composites without fillers. SEM images showed that spheres around $0.5-2.0 \mu \mathrm{m}$ were dispersed in both natural lacquer and composites. Natural lacquer sap contains various compounds such as urushiol, water, a gummy substance, a nitrogenous material, and laccase. ${ }^{18,19}$ These microsize spheres are compatible with the water-oil emulsion structure. In addition, the appearance of silica, which is byproduct of the condensation reaction between AATMS and urushiol, was not observed in the composite, indicating that the composite did not undergo considerable phase separation after the sol-gel reaction.

Figure 5 presents SEM images of bio-based composites using various fillers. All fillers were well-dispersed in the composites without interfacial defects, suggesting that the bio-based composite has high compatibility with all fillers. High loading of fillers in polymer materials and lack of interaction between them sometimes cause filler aggregation and interfacial defects between polymer and filler phases. ${ }^{29,30}$ In the present work, the ferrite and CI fillers were quite well dispersed in the binder of the composite at very high loading (e.g., 320-350wt\%) as presented in Figure 5. Carbon composites also dispersed well, but some CNTs aggregated into large bundles in the composites due to the high aggregation property of CNT. Therefore, we found that natural lacquer prevents some critical problems of the composites (e.g., large aggregations and interfacial defects) due to magnetic metals and carbon materials based on the excellent compatibility.

Figures 6 presents the frequency characteristics of reflection loss for bio-based composites using magnetic metals and carbon fillers, respectively. The summary of 
electromagnetic absorption properties of various materials using magnetic metals and carbons are listed in Tables 3 and 4, respectively. When an electromagnetic wave absorber has RL below $-20 \mathrm{~dB}$, which corresponds to over $99.00 \%$ of the microwave absorption property, the material can be used as an absorption material in this application. The base natural lacquer showed weak absorption peaks (below $-10 \mathrm{~dB}$ ) at 4.0 and $10.5 \mathrm{GHz}$. For magnetic metals, the minimum RL was observed at $3.5 \mathrm{GHz}$ for $280 \mathrm{wt} \%$ ferrite $(\mathrm{RL}<-20: 3.0-4.0 \mathrm{GHz})$, and at $9.3 \mathrm{GHz}$ for $200 \mathrm{wt} \% \mathrm{CI}(\mathrm{RL}<-20: 8.9-9.7 \mathrm{GHz})$. The minimum $\mathrm{RL}$ of the CI composites shifted from 9.3 to the lower frequency of $5.0 \mathrm{GHz}$ with increasing filler loading. As seen in Table 3, CI composites have a wide absorption band between 1.0 and $14.1 \mathrm{GHz}$ $(\mathrm{RL}<-20 \mathrm{~dB})$ depending on the thickness and loading. ${ }^{1-4}$ Fe-containing composites showed effective absorption of $\mathrm{RL}<-20 \mathrm{~dB}$ at $0.9-14.8 \mathrm{GHz} .^{5-10}$ Conversely, the absorption peaks for carbon composites were sharper than those for metal composites. For bio-based composites containing soot, the minimum RL was obtained around $16.9 \mathrm{GHz}(\mathrm{RL}<-20$ : 16.5-17.3 GHz) for $10 \mathrm{wt} \%$ and $9.0 \mathrm{GHz}(\mathrm{RL}<-20: 8.8-9.2 \mathrm{GHz})$ for $20 \mathrm{wt} \%$. The minimum RL of soot composites shifted to a higher frequency area with increased loading. This is might be because soot loading increased the dielectric polarization and attenuated electromagnetic waves by multiscatter and reflection. Therefore, the electromagnetic wave of soot composites is attenuated by eddy current loss. On the other hand, CNT-based composites showed a minimum $\mathrm{RL}$ value at $10.7 \mathrm{GHz}(\mathrm{RL}<-20$ : $10.4-11.0 \mathrm{GHz})$ for $5 \mathrm{wt} \%$ and 14.9 GHz $(\mathrm{RL}<-20: 14.6-15.2 \mathrm{GHz})$ for $10 \mathrm{wt} \%$. This absorption property of CNT is normally based on dielectric loss rather than magnetic loss. Therefore, we found that the natural lacquer kept the absorption properties of the fillers in the composites, and can be highly loaded with fillers, indicating that it can be used as a binder material for not only electromagnetic absorbers without a reduction of the absorption properties, but also the other composites. 

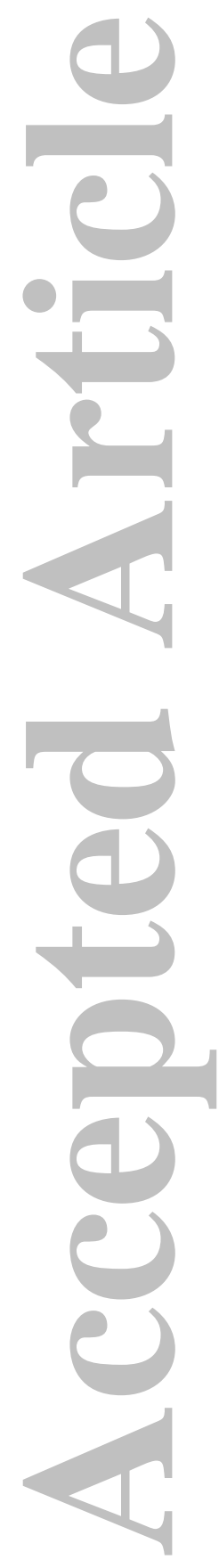

John Wiley \& Sons, Inc.

This article is protected by copyright. All rights reserved. 


\section{CONCLUTIONS}

We investigated the development of bio-based electromagnetic wave absorption materials from natural lacquer and various dielectric/magnetic fillers including ferrite, carbonyl iron, soot, and carbon nanotube. The composition of the natural lacquer-based composite was optimized by gel concentration, composite hardness, and drying properties. We found that this bio-based composite could contain quite high concentrations of magnetic metals due to the high compatibility of metals and natural lacquer. SEM images of bio-based composites showed well-dispersed fillers with the natural lacquer as a binder. Magnetic metal-based composites exhibited over 99\% electromagnetic absorption $(\mathrm{RL}<-20 \mathrm{~dB})$ in the frequency

range of $3.0-4.0 \mathrm{GHz}$ for $280 \mathrm{wt} \%$ ferrite and $8.9-9.7 \mathrm{GHz}$ for $200 \mathrm{wt} \%$ carbonyl iron, while carbon-based materials showed a frequency range of $16.5-17.3 \mathrm{GHz}$ for $10 \mathrm{wt} \%$ soot, 8.8-9.2 $\mathrm{GHz}$ for $20 \mathrm{wt} \%$ soot, $10.4-11.0 \mathrm{GHz}$ for $5 \mathrm{wt} \% \mathrm{CNT}$, and $14.6-15.2 \mathrm{GHz}$ for $10 \mathrm{wt} \% \mathrm{CNT}$. In addition, natural lacquer did not affect the absorption properties of fillers. Therefore, natural lacquer can serve as an effective binder for not only electromagnetic absorption materials without loss of the absorption properties, but also the other composites.

\section{ACKNOWLEDGEMENTS}

This research was partially supported by a Grant-in-Aid for the Japan Society for the Promotion of Science (JSPS) Fellows (2410856). We acknowledge to Associate Professor Hiroshi Katsumata, Meiji University, Japan, for electromagnetic wave absorption experiment.

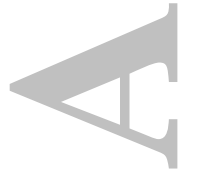




\section{REFERENCES}

1. S. Jia, F. Luo, Y. Qing, W. Zhouand D. Zhu, Physica B, 405, 3611-3615 (2010).

2. G. Tong, W. Wu, Q. Hua, Y. Miao, J. Guanand H. Qian, J. Alloys Compd., 509, 451-456 (2011).

3. B. Wang, J. Wei, L. Qiao, T. Wangand F. Li, J. Magn. Magn. Mater., 324, 761-765 (2012).

4. B. Wang, J. Wei, Y. Yang, T. Wangand F. Li, J. Magn. Magn. Mater, 323, 1101-1103 (2011).

5. M. Terada, M. Itoh, J. R. Liuand K.-i. Machida, J. Magn. Magn. Mater, 321, 1209-1213 (2009).

6. L. Wang, F. Heand Y. Wan, J. Alloys Compd., 509, 4726-4730 (2011).

7. C. Qiang, J. Xu, Z. Zhang, L. Tian, S. Xiao, Y. Liuand P. Xu, J. Alloys Compd., 506, 93-97 (2010).

8. D.-L. Zhao, X. Liand Z.-M. Shen, J. Alloys Compd., 471, 457-460 (2009).

9. J. R. Liu, M. Itohand K.-I. Machida, J. Alloys Compd., 389, 265-269 (2005).

10. Y. X. Gong, L. Zhen, J. T. Jiang, C. Y. Xuand W. Z. Shao, J. Magn. Magn. Mater, 321, 3702-3705 (2009).

11. J. Liu, Y. Fengand T. Qiu, J. Magn. Magn. Mater., 323, 3071-3076 (2011).

12. D. Y. Kim, Y. C. Chung, T. W. Kangand H. C. Kim, IEEE Transactions on Magnetics, 32, 555-558 (1996).

13. L. Liu, Y. Duan, S. Liu, L. Chenand J. Guo, J. Magn. Magn. Mater, 322, 1736-1740 (2010).

14. S. Kanehashi, R. Masuda, K. Yokoyama, T. Kanamoto, H. Nakashimaand T. Miyakoshi, J. Appl. Polym. Sci., 132, n/a-n/a (2015).

15. S. Kanehashi, K. Yokoyama, R. Masuda, T. Kidesaki, K. Nagaiand T. Miyakoshi, J. Appl. Polym. Sci., 130, 2468-2478 (2013).

16. S. Kanehashi, T. Nagasawa, M. Kobayashi, S. L. Lee, M. Nakamura, S. Sato, M. F. Beristain, T. Ogawa, T. Miyakoshiand K. Nagai, J. Appl. Polym. Sci., 130, 277-286 (2013).

17. H. Sun, S. Kanehashi, K. Tsuchiya, and K. Ogino, Chem. Lett., 45, 439-441 (2016).

18. N. Niimura, T. Miyakoshi, J. Onodera and T. Higuchi, Rap. Commun. Mass Spectrosc., 10, 1719-1724 (1996).

19. R. Lu, S. Harigaya, T. Ishimura, K. Nagase and T. Miyakoshi, Prog. Org. Coat., 51, 238-243 (2004).

John Wiley \& Sons, Inc.

This article is protected by copyright. All rights reserved. 
20. T. Honda, R. Lu, R. Sakai, T. Ishimura and T. Miyakoshi, Prog. Org. Coat., 61, 68-75 (2008).

21. R. Lu, T. Yoshida and T. Miyakoshi, Polym. Rev., 53, 153-191 (2013).

22. S. Kanehashi, H. Oyagi, R. Lu and T. Miyakoshi, Prog. Org. Coat., 77, 24-29 (2014).

23. T. Honda, R. Luand T. Miyakoshi, Prog. Org. Coat., 56, 279-284 (2006).

24. T. Ishimura, R. Lu, K. Yamasaki and T. Miyakoshi, Prog. Org. Coat., 69, 12-15 (2010).

25. R. Lu, Y.-Y. Wan, T. Honda, T. Ishimura, Y. Kamiya and T. Miyakoshi, Prog. Org. Coat., 57, 215-222 (2006).

26. T. Ishimura, R. Lu, K. Yamasaki and T. Miyakoshi, Prog. Org. Coat., 62, 193-198 (2008).

27. T. Iwamaru, H. Katsumata, S. Uekusa, H. Ooyagi, T. Ishimura and T. Miyakoshi, Physics Procedia, 23, 69-72 (2012).

28. A. M. Nicolsonand G. F. Ross, IEEE Transactions on Instrumentation and Measurement, 19, 377-382 (1970).

29. S. Kanehashi, H. Gu, R. Shindo, S. Sato, T. Miyakoshi and K. Nagai, J. Appl. Polym. Sci., 128, 3814-3823 (2013).

30. S. Kanehashi, G. Chen, C. Scholes, B. Ozcelik, C. Hua, L. Ciddor, P. Southon, D. D’Alessandro, S. Kentish, J. Membr. Sci., 482, 49-55 (2015).

John Wiley \& Sons, Inc.

This article is protected by copyright. All rights reserved. 


\section{Figure Captions}

Figure 1 Chemical structures of urushiol, BPAE, and AATMS.

Figure 2 Gel contents of natural lacquer and bio-based composites.

Figure 3 SEM images of electromagnetic wave absorption fillers.

Figure 4 Cross-sectional SEM images of natural lacquer and bio-based composites
without filler.
Figure 5
Figure 6
Fross-sectional SEM images of bio-based composites with various fillers.
magnetic metal and carbon fillers.

John Wiley \& Sons, Inc. 
Table 1 Molecular weight properties of bio-based composites

\begin{tabular}{|c|c|c|c|c|c|c|c|c|}
\hline \multirow{2}{*}{ Entry } & \multicolumn{2}{|c|}{ Additive content (wt $\%$ ) } & \multicolumn{3}{|c|}{ Content ratio (\%) ${ }^{\text {(a) }}$} & \multicolumn{3}{|c|}{ Molecular weight } \\
\hline & AATMS & BPAE & Monomer & Oligomer & Polymer & $M_{n}$ & $M_{w}$ & $M_{w} / M_{n}$ \\
\hline $1^{\text {(b) }}$ & 0 & 0 & 49.1 & 45.7 & 5.2 & 510 & 2140 & 4.2 \\
\hline 2 & 5 & 5 & 49.5 & 44.9 & 5.6 & 320 & 2350 & 7.4 \\
\hline 3 & 5 & 10 & 52.3 & 41.7 & 6.0 & 290 & 2370 & 8.3 \\
\hline 4 & 5 & 15 & 52.1 & 41.5 & 6.4 & 310 & 2440 & 7.8 \\
\hline 5 & 5 & 20 & 55.7 & 39.1 & 5.2 & 270 & 2170 & 8.0 \\
\hline 6 & 10 & 5 & 41.1 & 44.0 & 14.9 & 710 & 4740 & 6.7 \\
\hline 7 & 10 & 10 & 37.8 & 44.7 & 17.5 & 510 & 5320 & 10.4 \\
\hline 8 & 10 & 15 & 41.8 & 43.0 & 15.2 & 470 & 4810 & 10.3 \\
\hline 9 & 10 & 20 & 43.1 & 41.7 & 15.2 & 480 & 5060 & 10.7 \\
\hline 10 & 15 & 5 & 26.0 & 50.5 & 23.5 & 790 & 6980 & 8.8 \\
\hline 11 & 15 & 10 & 29.0 & 47.2 & 23.8 & 760 & 7380 & 9.8 \\
\hline 12 & 15 & 15 & 31.4 & 45.4 & 23.3 & 660 & 7130 & 10.8 \\
\hline 13 & 15 & 20 & 31.4 & 43.4 & 22.2 & 610 & 6780 & 11.1 \\
\hline 14 & 20 & 5 & 20.3 & 48.3 & 31.4 & 1320 & 10400 & 7.8 \\
\hline 15 & 20 & 10 & 19.9 & 50.8 & 29.2 & 1120 & 9790 & 8.8 \\
\hline 16 & 20 & 15 & 20.1 & 50.5 & 29.4 & 1140 & 9320 & 8.2 \\
\hline 17 & 20 & 20 & 24.4 & 48.4 & 27.2 & 1070 & 7560 & 7.1 \\
\hline
\end{tabular}

(a) Oligomer: dimer $\leqq$ molecular weight $<10,000 \mathrm{~g} / \mathrm{mol}$, polymer: molecular weight $\geqq 10,000 \mathrm{~g} / \mathrm{mol}$ 
Table 2 Drying property and hardness of bio-based composites

\begin{tabular}{|c|c|c|c|c|c|c|c|c|c|c|c|}
\hline \multirow{2}{*}{ Entry } & \multicolumn{2}{|c|}{ Additive content (wt $\%$ ) } & \multicolumn{3}{|c|}{ Drying property (h) ${ }^{(a)}$} & \multicolumn{6}{|c|}{ Hardness ${ }^{(b)}$} \\
\hline & AATMS & BPAE & $\mathrm{DF}$ & $\mathrm{TF}$ & HD & 1day & 3days & 5 days & 7 days & 15 days & 30 days \\
\hline $1^{\text {(c) }}$ & 0 & 0 & 18.5 & 23.1 & $24<$ & $\mathrm{TF}$ & $\mathrm{HD}$ & $\mathrm{HD}$ & $\mathrm{HD}$ & $6 \mathrm{~B}$ & - \\
\hline 2 & 5 & 5 & 0.9 & 1.7 & 3.8 & $4 \mathrm{~B}$ & $4 \mathrm{~B}$ & $3 B$ & $\mathrm{HB}$ & $3 \mathrm{H}$ & $8 \mathrm{H}$ \\
\hline 3 & 5 & 10 & 0.5 & 1.5 & 3.9 & $5 \mathrm{~B}$ & $4 \mathrm{~B}$ & $3 B$ & $\mathrm{HB}$ & $3 \mathrm{H}$ & $8 \mathrm{H}$ \\
\hline 4 & 5 & 15 & 0.9 & 1.7 & 6.8 & $6 \mathrm{~B}$ & $4 \mathrm{~B}$ & $3 \mathrm{~B}$ & $2 \mathrm{~B}$ & $\mathrm{H}$ & $4 \mathrm{H}$ \\
\hline 5 & 5 & 20 & 1.2 & 1.9 & 8.9 & HD & $5 B$ & 4B & $3 \mathrm{~B}$ & $\mathrm{H}$ & $4 \mathrm{H}$ \\
\hline 6 & 10 & 5 & 1.4 & 2.5 & 18.2 & $5 B$ & $2 \mathrm{~B}$ & $2 B$ & B & $2 \mathrm{H}$ & $4 \mathrm{H}$ \\
\hline 7 & 10 & 10 & 2.0 & 3.5 & 18.4 & $6 \mathrm{~B}$ & $4 B$ & $3 B$ & $2 \mathrm{~B}$ & $\mathrm{H}$ & $\mathrm{H}$ \\
\hline 8 & 10 & 15 & 4.6 & 8.9 & 23.2 & HD & $6 \mathrm{~B}$ & $5 B$ & $3 B$ & $\mathrm{H}$ & $\mathrm{H}$ \\
\hline 9 & 10 & 20 & 5.3 & 8.0 & 23.4 & HD & HD & $6 \mathrm{~B}$ & $4 B$ & HB & $\mathrm{H}$ \\
\hline 10 & 15 & 5 & 3.5 & 8.1 & $24<$ & $\mathrm{TF}$ & HD & HD & HD & HD & $5 \mathrm{~B}$ \\
\hline 11 & 15 & 10 & 3.9 & 9.2 & $24<$ & $\mathrm{TF}$ & HD & HD & HD & $6 \mathrm{~B}$ & $5 \mathrm{~B}$ \\
\hline 12 & 15 & 15 & 2.9 & 6.6 & $24<$ & $\mathrm{TF}$ & HD & HD & $6 \mathrm{~B}$ & $5 \mathrm{~B}$ & $3 B$ \\
\hline 13 & 15 & 20 & 5.0 & 10.6 & 23.2 & HD & HD & HD & $6 \mathrm{~B}$ & $3 \mathrm{~B}$ & $\mathrm{HB}$ \\
\hline 14 & 20 & 5 & 2.7 & 7.3 & $24<$ & $\mathrm{TF}$ & HD & HD & HD & HD & $5 B$ \\
\hline 15 & 20 & 10 & 2.7 & 4.0 & 16.3 & HD & HD & HD & HD & HD & $4 \mathrm{~B}$ \\
\hline 16 & 20 & 15 & 1.5 & 3.8 & 23.4 & HD & HD & HD & HD & $5 \mathrm{~B}$ & $3 B$ \\
\hline 17 & 20 & 20 & 0.9 & 4.6 & 13.1 & HD & $6 \mathrm{~B}$ & $6 \mathrm{~B}$ & $6 \mathrm{~B}$ & $4 B$ & $3 \mathrm{~B}$ \\
\hline
\end{tabular}

(a) DF: dust free dry, TF: touch free dry, and HD: harden dry (based on JIS-K-5400)

(b) Pencil hardness: $\mathrm{HD}<<6 \mathrm{~B}<$ B $<\mathrm{HB}<$ F $<$ H $<<9 \mathrm{H}$ 
Table 3 Electromagnetic wave absorption properties of bio-based composites using various magnetic metals

\begin{tabular}{|c|c|c|c|c|c|c|}
\hline \multirow{2}{*}{ Filler } & \multirow{2}{*}{$\begin{array}{l}\text { Filler loading } \\
\quad\left(w t^{\circ} \%\right)\end{array}$} & \multirow{2}{*}{$\begin{array}{l}\text { Thickness } \\
(\mathrm{mm})\end{array}$} & \multicolumn{2}{|c|}{ Minimum RL } & \multirow{2}{*}{$\begin{array}{c}\mathrm{RL}<-20 \mathrm{~dB} \\
(\mathrm{GHz})\end{array}$} & \multirow{2}{*}{ Reference } \\
\hline & & & Frequency $(\mathrm{GHz})$ & $\mathrm{RL}(\mathrm{dB})$ & & \\
\hline Ferrite & 280 & 5.0 & 3.5 & -37 & $3.0-4.0$ & This work \\
\hline $\mathrm{CI}$ & 200 & 5.0 & 9.3 & -22 & $8.9-9.7$ & This work \\
\hline $\mathrm{CI}$ & 75 & 1.7 & 8.8 & -29 & $8.4-9.3$ & {$[1]$} \\
\hline $\mathrm{Ni}$-coated CI & 75 & 1.7 & 10.2 & -30 & $9.5-10.8$ & [1] \\
\hline CI & 35 (vol\%) & 1.5 & 14.1 & -23 & $13.3-14.9$ & [2] \\
\hline $\mathrm{CNT} / \mathrm{CI}$ & $2.2 / 35(\mathrm{vol} \%)$ & 1.5 & 11.2 & -34 & $10.5-11.9$ & [2] \\
\hline $\mathrm{CNT} / \mathrm{CI}$ & $2.2 / 35\left(\mathrm{vol}^{2} \%\right)$ & 1.8 & 9.2 & -31 & $8.5-9.8$ & [2] \\
\hline $\mathrm{CNT} / \mathrm{CI}$ & $4.4 / 35\left(\operatorname{vol}^{2} \%\right)$ & 3.0 & 4.0 & -42 & $3.6-4.4$ & [2] \\
\hline $\mathrm{CI}$ & 30 & 1.5 & 11.0 & -22 & $10.0-12.0$ & [3] \\
\hline $\mathrm{CI}$ & 30 & 2.0 & 7.8 & -33 & $7.0-8.6$ & [3] \\
\hline $\mathrm{CI}$ & 50 & 2.0 & 9.0 & -33 & $8.5-9.5$ & [4] \\
\hline $\mathrm{CI}$ & 50 & 4.0 & 1.0 & -23 & $0.8-1.2$ & [4] \\
\hline Dendrite-Fe & 70 & 1.5 & 7.8 & -33 & $7.0-8.6$ & {$[5]$} \\
\hline Dendrite-Fe & 70 & 2.3 & 11.0 & -24.5 & $10.0-11.0$ & [5] \\
\hline $\mathrm{Fe}_{3} \mathrm{C} /$ Carbon & 70 & 3.2 & 4.4 & -32 & $4.1-4.7$ & [5] \\
\hline $\mathrm{Fe}_{3} \mathrm{C} /$ Carbon & 70 & 6.5 & 2.0 & -25 & $1.8-2.2$ & [5] \\
\hline $\mathrm{Fe}_{3} \mathrm{C} /$ Carbon & 70 & 13.5 & 0.85 & -24 & $0.8-0.9$ & [5] \\
\hline $\mathrm{Fe} / \mathrm{Y}_{2} \mathrm{O}_{3}$ & 80 & $3.0-5.0$ & 2.6 & -36 & $2.0-3.5$ & [8] \\
\hline $\mathrm{FeCo} / \mathrm{Y}_{2} \mathrm{O}_{3}$ & 80 & $2.8-7.0$ & 3.2 & -55 & $1.9-5.4$ & [8] \\
\hline $\mathrm{FeCo} / \mathrm{Y}_{2} \mathrm{O}_{3}$ & 80 & $3.1-7.2$ & 3.1 & -37 & $2.1-5.0$ & [8] \\
\hline $\mathrm{FeCo} / \mathrm{Y}_{2} \mathrm{O}_{3}$ & 80 & $2.0-7.4$ & 3.9 & -45 & $2.2-9.7$ & [8] \\
\hline $\mathrm{FeCo} / \mathrm{C}$ & 30 & $1.7-3.0$ & 10.8 & -48.2 & $5.7-11.5$ & [9] \\
\hline $\mathrm{CoFe}$ & 15 & $2.1-2.3$ & 14.8 & -23 & $11.8-15.2$ & {$[10]$} \\
\hline
\end{tabular}


Table 4 Electromagnetic wave absorption properties of bio-based composites using carbon materials

\begin{tabular}{ccccccc}
\hline Filler & $\begin{array}{c}\text { Filler loading } \\
(\mathrm{wt} \%)\end{array}$ & $\begin{array}{c}\text { Thickness } \\
(\mathrm{mm})\end{array}$ & \multicolumn{2}{c}{ Minimum RL } & RL $<-20 \mathrm{~dB}$ \\
$(\mathrm{GHz})$ & Reference \\
\hline Soot & 10 & 5.0 & 16.9 & -33 & $16.5-17.3$ & This work \\
Soot & 20 & 5.0 & 9.0 & -28 & $8.8-9.2$ & This work \\
$\mathrm{CNT}$ & 5 & 5.0 & 10.7 & -27 & $10.4-11.0$ & This work \\
$\mathrm{CNT}$ & 10 & 5.0 & 14.9 & -25 & $14.6-15.2$ & This work \\
\hline $\mathrm{CNT} / \mathrm{CI}$ & $2.2 / 35(\mathrm{vol} \%)$ & 1.5 & 11.2 & -34 & $10.5-11.9$ & {$[2]$} \\
$\mathrm{CNT} / \mathrm{CI}$ & $2.2 / 35(\mathrm{vol} \%)$ & 1.8 & 9.2 & -31 & $8.5-9.8$ & {$[2]$} \\
$\mathrm{CNT} / \mathrm{CI}$ & $4.4 / 35(\mathrm{vol} \%)$ & 3.0 & 4.0 & -42 & $3.6-4.4$ & {$[2]$} \\
$\mathrm{Fe}_{3} \mathrm{C} / \mathrm{Carbon}$ & 70 & 3.2 & 4.4 & -32 & $4.1-4.7$ & {$[5]$} \\
$\mathrm{Fe}_{3} \mathrm{C} / \mathrm{Carbon}$ & 70 & 6.5 & 2.0 & -25 & $1.8-2.2$ & {$[5]$} \\
$\mathrm{Fe}_{3} \mathrm{C} / \mathrm{Carbon}$ & 70 & 13.5 & 0.85 & -24 & $0.8-0.9$ & {$[5]$} \\
$\mathrm{CNT}$ & 5 & 1.0 & 11.3 & -23.5 & $10.8-11.8$ & {$[6]$} \\
$\mathrm{Fe}-\mathrm{CNT}$ & 10 & 1.0 & 13.2 & -32 & $12.6-13.8$ & {$[6]$} \\
$\mathrm{FeCo} / \mathrm{C}$ & 30 & $1.7-3.0$ & 10.8 & -48.2 & $5.7-11.5$ & {$[9]$} \\
\hline
\end{tabular}




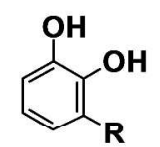

$\mathbf{R}$

Urushiol

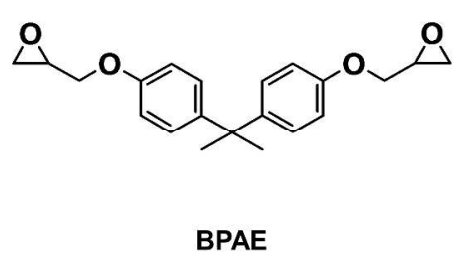

BPAE<smiles>NCNCC[Si]([O-])(O)O</smiles>

AATMS

Figure 1

$338 \times 190 \mathrm{~mm}$ (300 x 300 DPI)

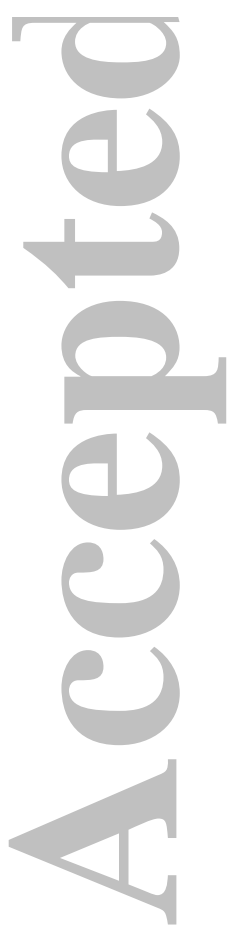

John Wiley \& Sons, Inc.

This article is protected by copyright. All rights reserved. 


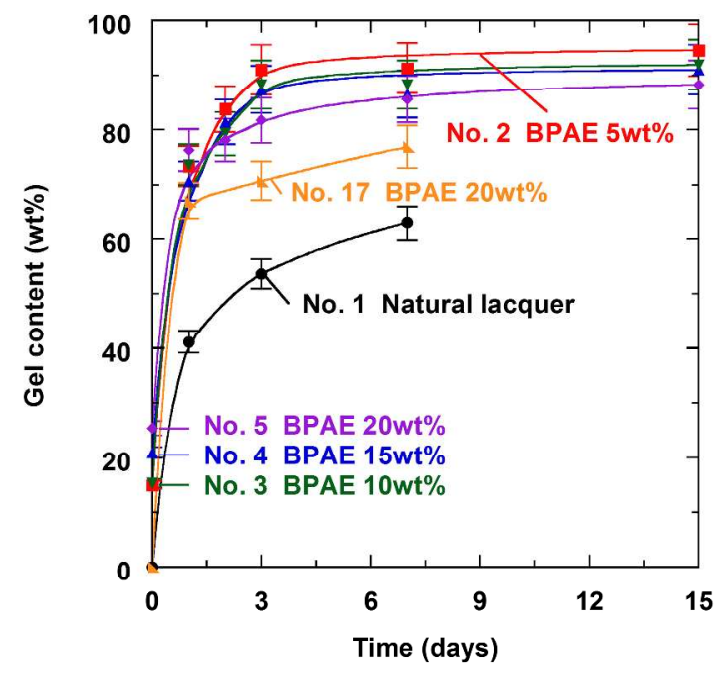

Figure 2

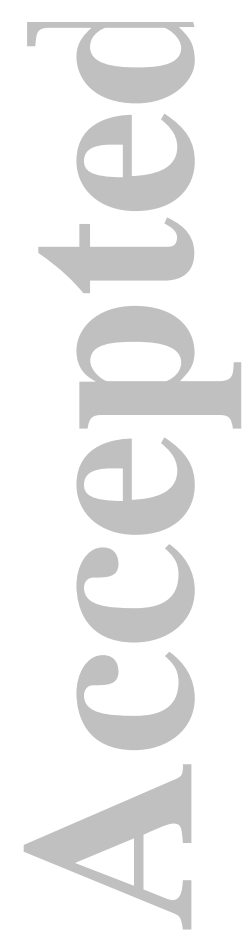

$338 \times 190 \mathrm{~mm}(300 \times 300 \mathrm{DPI})$

John Wiley \& Sons, Inc.

This article is protected by copyright. All rights reserved. 

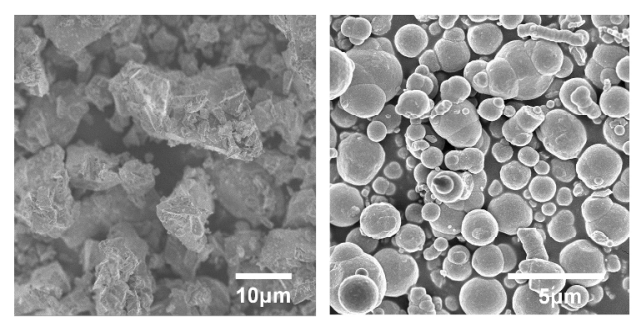

Ferrite

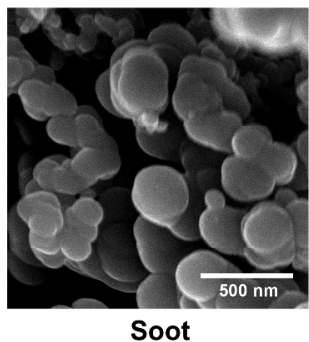

Carbonyl iron (Cl)

Figure 3

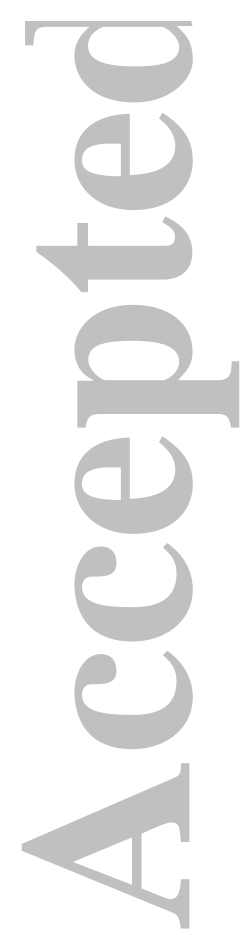

$338 \times 190 \mathrm{~mm}(300 \times 300 \mathrm{DPI})$

John Wiley \& Sons, Inc.

This article is protected by copyright. All rights reserved. 


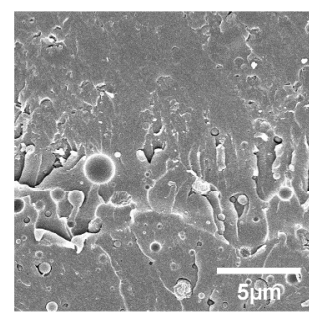

Natural lacquer

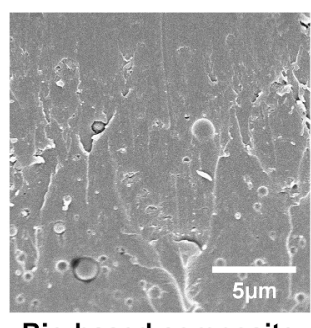

Bio-based composite

Figure 4

$338 \times 190 \mathrm{~mm}(300 \times 300$ DPI $)$

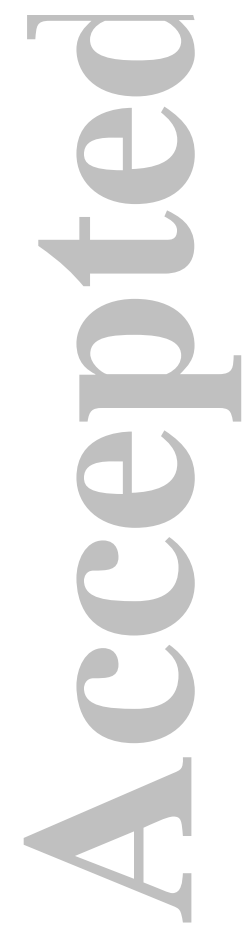

John Wiley \& Sons, Inc.

This article is protected by copyright. All rights reserved. 

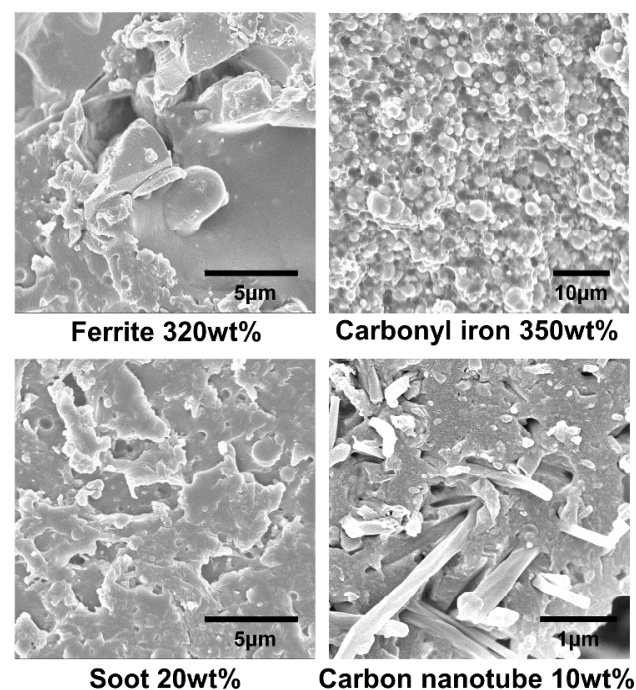

Figure 5

$338 \times 190 \mathrm{~mm}(300 \times 300$ DPI $)$

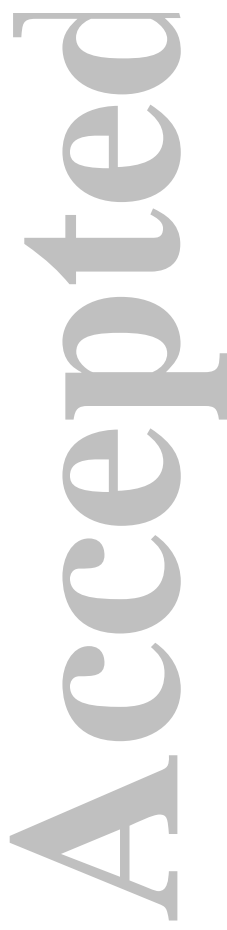

John Wiley \& Sons, Inc.

This article is protected by copyright. All rights reserved. 

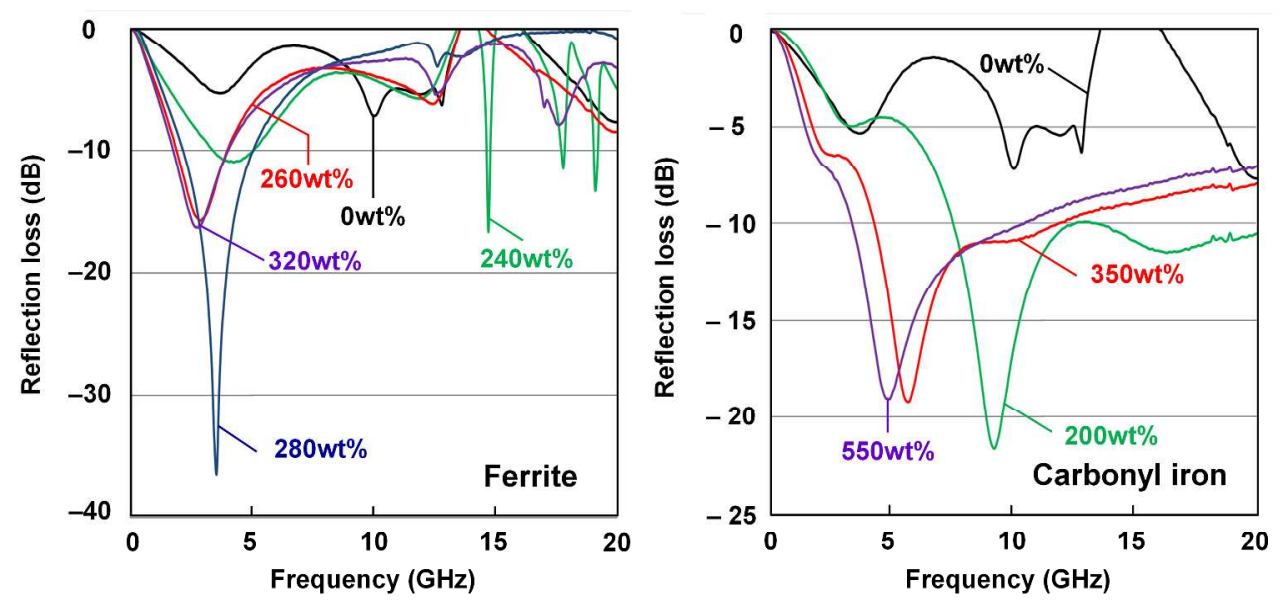

Figure 6-1

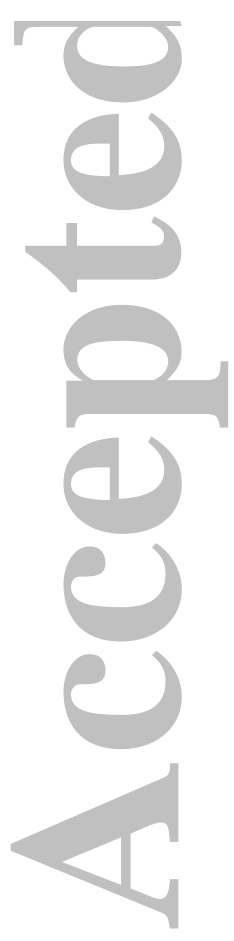

$338 \times 190 \mathrm{~mm}$ (300 x 300 DPI)

John Wiley \& Sons, Inc.

This article is protected by copyright. All rights reserved. 

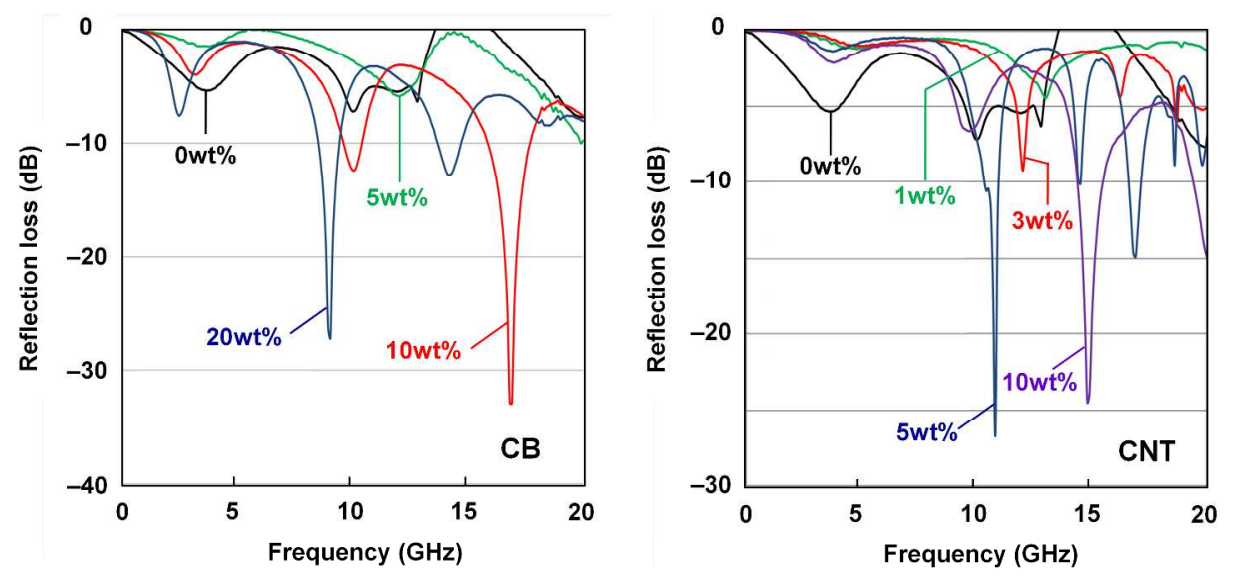

Figure 6-2

$338 \times 190 \mathrm{~mm}(300 \times 300 \mathrm{DPI})$

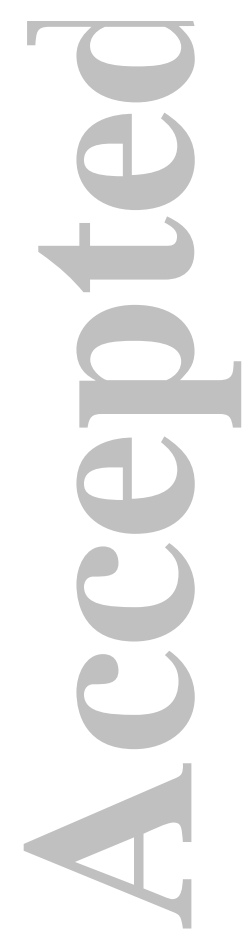

John Wiley \& Sons, Inc.

This article is protected by copyright. All rights reserved. 


\section{University Library}

\section{- M M N E R VA A gateway to Melbourne's research publications}

Minerva Access is the Institutional Repository of The University of Melbourne

Author/s:

Kanehashi, S;Oyagi, H;Iwamaru, T;Ando, S;Nagai, K;Uekusa, S;Miyakoshi, T

Title:

Development of biobased microwave absorbing composites with various magnetic metals and carbons

Date:

2016-11-20

Citation:

Kanehashi, S., Oyagi, H., Iwamaru, T., Ando, S., Nagai, K., Uekusa, S. \& Miyakoshi, T. (2016). Development of biobased microwave absorbing composites with various magnetic metals and carbons. JOURNAL OF APPLIED POLYMER SCIENCE, 133 (44), https:// doi.org/10.1002/app.44131.

Persistent Link:

http://hdl.handle.net/11343/291594 